\title{
Consequences Of Domestic Violence During Pregnancy
}

\author{
Shakila A. Rehman \\ Department of Geography \\ University of Karachi \\ \& \\ Muhammad Shahid \\ Department of Social Work \\ University of Karachi
}

\begin{abstract}
Although gender-based violence is prevalent in all societies however it is more widespread in Pakistan. Women of all ages, from birth to old age, are victims of violence. The consequences of gender-based violence are devastating not only for women but for the whole family. Violence against women is mostly treated as a private matter and hence goes unreported and thus its actual prevalence remains little known. There are many forms of gender-based-violence. Among these, violence during pregnancy is some what less discussed. The present study examines some aspects of violence during pregnancy by the husband, and looks at its health consequences. The study was conducted in a Katchi abadi (unauthorized settlement) of Karachi, among poor women. Findings show that prevalence of violence by husbands during pregnancy is high among study population.

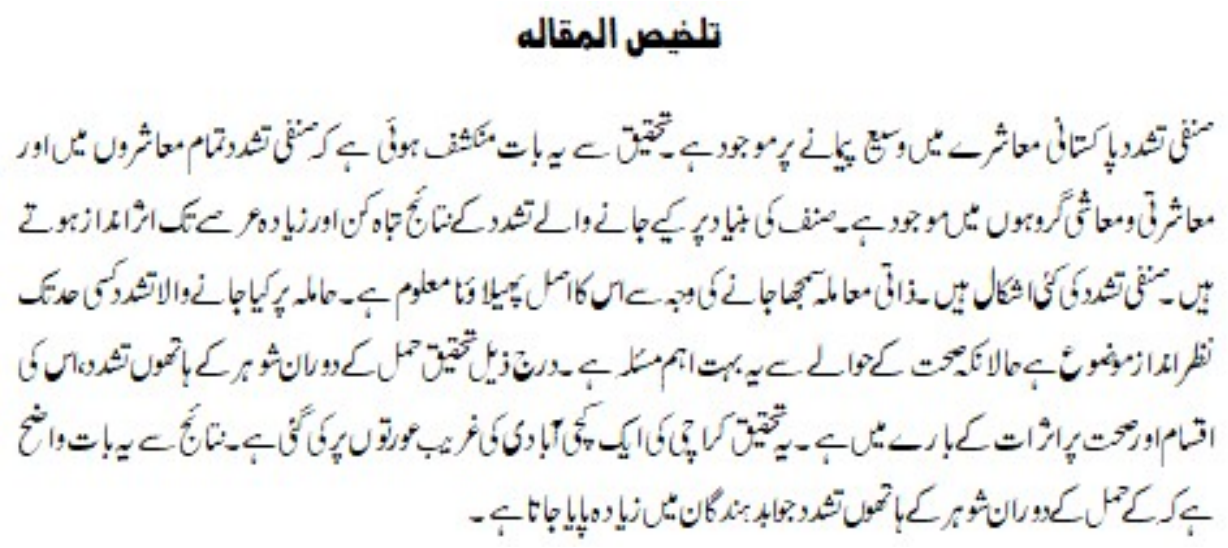

\section{Introduction}

Globally, the most common form of violence against women is abuse by their husbands or intimate partners. According to estimates, one in three women worldwide are physically assaulted, sexually coerced or otherwise abused in their lifetime (Heise et al. 1999). Article 1 of the Declaration on the Elimination of Violence Against Women, adopted by the United Nations General Assembly in 1993 defines violence against 
women as "any act of gender-based violence that results in, is likely to result in physical, sexual or mental harm or suffering to women including threats of such acts, coercion or arbitrary deprivation liberty, whether occurring in public or private life" (UN 1993). Thus, violence against women is not only violation of human rights but it also poses a serious public health concern. Recognizing this, the World Health Assembly in 1996 declared violence to be a public health priority issue. Subsequently the World Health Organization (1997) defined domestic violence as "the range of sexually, psychologically and physically coercive acts used against adult and adolescent women by current or harmful intimate partners."

According to a review, including studies from China, Egypt, Mexico, India, Nicaragua, Pakistan, Saudi Arabia, and South Africa, the prevalence of any form of violence during pregnancy is 3.4 percent to 4.0 percent in industrialized countries and 3.8 percent to 31.7 percent in developing countries (Campbell et al. 2004). A study by WHO (2005) found that the number of ever married pregnant women physically abused during last pregnancy ranged from 1 percent in Japan to 28 percent in Peru. Most common form of physical violence was kicking or punching of the abdomen of the pregnant woman. About 11 percent to 44 percent of ever abused pregnant women were reported being assaulted during pregnancy. Majority of the respondents beaten by their partners or husbands during pregnancy had experienced physical violence before. Between 13 percent in Ethiopia and 50 percent in urban Brazil and Serbia and Montenegro, said they were beaten for the first time during pregnancy. Studies show that violence during pregnancy is generally linked both to a history of violence prior to the pregnancy and prevailing cultural norms. Campbell et al. (2004) found that majority of women who are abused in pregnancy were also abused before and after the pregnancy. A minority of women reported that they experienced violence for the first time during pregnancy.

Violence during pregnancy can have serious health consequences for women and their children. Low birth weight of infant may be a direct or indirect consequence of violence. They are more likely to delay seeking prenatal care etc. Heise et al. (1999) reviewed a large number of literature and found several obstetric risk factors, associated with violence during pregnancy. Pregnant women who have experienced violence are more likely to delay seeking care and to gain in sufficient weight, more likely to have a history of Sexually Transmitted Infections, unwanted or mistimed pregnancies, vaginal and cervical infections, kidney infections and bleeding during pregnancy.

Heise et al. (1999) also mentions the impact of violence during pregnancy on fetus and infant. It is associated with increased risk of miscarriage, abortions, premature labour, total distress, and death and infant also maternal death.

Sexual and physical violence increases women's risk for many gynecological disorders such as chronic pelvic pain, irregular vaginal bleeding, vaginal discharge, painful 
menstruation, pelvic inflammatory disease etc. Newberger et al. (1992) mentioned a number of physical effects of violence during pregnancy i.e. insufficient weight gain, vaginal, cervical, kidney infections, vaginal bleeding, abdominal trauma, hemorrhage, exacerbation of chronic illnesses, complications during labour, delayed prenatal care, miscarriage, low birth weight, ruptured membranes, abruption placenta, uterine infection, total bruising, fractures and hematomas death. Newberger et al. (1992) also mentioned that pregnant women who are abused by their partners/husbands have a higher risk for stress, depression and addiction to tobacco, alcohol and drugs. The long term psychological consequences of violence during pregnancy can have a severely detrimental effect on a child's psychological development.

Low birth weight may be a direct or indirect consequence of violence, such as preterm delivery may be due to direct abdominal trauma. In Nicaragua, women who experienced physical or sexual violence during pregnancy were four times likely to deliver a low weight baby and six times more likely to experience an infant death (Valladares et al. 2002; Asling et al. 2003).Violence may also affect birth weight indirectly, through changes in physiology, increased levels of stress hormones and immunological factors and behavioral mechanisms. It is also revealed from studies that violence affects women's ability to obtain adequate nutrition, rest, exercise and medical care. Women experiencing physical or sexual violence are likely to suffer from a variety of mental health disorders, such as depression, anxiety and post traumatic stress syndrome. Physical violence is often accompanied by feelings of powerlessness, social isolation and economic dependency. The child deaths may have been due to direct trauma violence impacts child health through maternal stress or care giving behaviors.

Gender-based violence during pregnancy is common in many countries. The Centre for Disease Control (CDC),US, defines domestic violence during pregnancy as "Physical, sexual or psychological/emotional violence, or threats of physical or sexual violence that are inflicted on a pregnant woman". Violence against women is a serious social and medical problem and violence during pregnancy may be more harmful and poses a significant additional threat to fetus (Muhajarine and D'Arey, 1999).

Although research studies about violence against women are increasing, relatively little is known about the prevalence, reasons, correlates and consequences on women and their children of violence during pregnancy. Domestic violence is a common problem during pregnancy in many countries. Estimates of the prevalence of pregnancy related violence vary due to difference in research design, methodology adopted and measures used etc. In addition, it is also observed that while hospital or clinical based studies find association between pregnancy and prevalence of violence, many national surveys do not find the same. 


\section{Objectives of the Study}

The present study was conducted to know the prevalence of gender-based violence during pregnancy among women, mostly poor women living in the squatter settlements of Karachi.

\section{Methods of Research}

The study is based on a cross-sectional survey conducted in 2006, among poor women. Data was collected from Madina Colony (a squatter settle) located in the Gulshan-e-Iqbal area of Karachi, Pakistan. The study population was married, having at least one pregnancy during the last three years at the time of survey. A total of 50 women were selected for the study and data was collected using semi-structured questionnaires and informal discussion. Respondents were selected through systematic random sampling. The questionnaire was pre-tested.

Madina Colony came into existence in the 1970's. A large majority of the people are Punjabi/Saraiki speaking. The questionnaire was in Urdu language but the interviewers were able to understand Punjabi very well. The respondents' perception about violence varied, most of them perceived that it is the right of husbands, some of them considered only severe wife battering as violence.

\section{Profile of Respondents}

All respondents were currently married, large majority fell in the age group 20-39, about 56 percent were living in extended families or joint families, only 22 percent were literate. Those who were literate had elementary schooling for no more than three years. About 56 percent respondents were employed or working. They worked as domestic worker (house maid) or home-based worker/self-employed. About 16 percent respondents told that at the time of survey their husbands were unemployed, 36 percent were working as self-employed such as selling fruits or vegetables, 48 percent were working as servants or labourers. Although in many households both husband and wife were working and earning, their average monthly income was low. Additionally, their household size was also large thus per person income was too low. Average number of children born was 5.1, and 24 percent women had 6 or more children.

\section{Verbal Violence during Pregnancy}

Verbal violence during pregnancy seemed to be more prevalent then physical violence. The present study confirms the findings of an earlier study conducted by Abbasi (2003) in Karachi in which 53 percent pregnant women reported verbal abuse by their husbands. Table 1 below shows that only 48 percent respondents reported their husbands did not 
abuse them verbally. Some of them said that their husbands were violent, but during pregnancy they changed their behaviour and did not abuse them verbally or physically.

Table 1

Ever had Experienced Verbal Violence during Pregnancy

\begin{tabular}{|l|c|c|}
\hline Response & Number & Percentage \\
\hline Yes & 26 & 52.00 \\
\hline No & 24 & 48.00 \\
\hline Total & 50 & 100.00 \\
\hline
\end{tabular}

Fifty two percent respondents affirmed verbal abuse by their spouses and reported that the most repeated form of it was criticizing them (Table 2). More than half of the respondents also felt tortured by the use of insulting and abusive language. About 26 percent women shared with us how their husbands' abusive treatment caused them deep anguish which created mental depression, thus impacting their mental health. Respondents said that their husbands often threatened them of marrying another woman. The abusive husbands warned them that the birth of a daughter, instead of a son, would result in dire consequences-the break-up of their marriage. Some also reported that their husbands threatened them by saying that in case of the birth of a girl, they would be forced to go back to their parents' home. Some of our respondents described to us how during their first pregnancy their husbands' demand to have a son and not a daughter caused them depression and mental tension. There were some good stories too. A few told us said that for them pregnancy was the peaceful time and their husbands took care of them and showed understanding.

Table 2

Forms of Verbal Violence

\begin{tabular}{|l|c|c|}
\hline Forms of verbal violence & Number & Percentage \\
\hline Criticizing & 26 & 52.00 \\
\hline Scolding & 22 & 44.00 \\
\hline Threatening & 13 & 26.00 \\
\hline Insulting/abusive language & 24 & 48.00 \\
\hline
\end{tabular}

\section{Physical Violence during Pregnancy}

Table 3 shows that 36 percent respondents reported that they had experienced physical violence during pregnancy. In a study conduced by Abbasi et al. (2003) found that 47 percent pregnant women reported physical violence by their husbands. 


\section{Table 3}

\section{Ever had Experienced Physical Violence during Pregnancy}

\begin{tabular}{|l|c|c|}
\hline Response & Number & Percentage \\
\hline Yes & 18 & 36.00 \\
\hline No & 32 & 64.00 \\
\hline Total & 50 & 100.00 \\
\hline
\end{tabular}

Respondents of the study reported various forms of physical violence. The most common forms were pushing and slapping followed by pulling of hair. Few respondents reported that their husbands tried to throw objects at them such as glass, shoe, etc. One respondent informed that her husband once tried to throw hot tea over her while another respondent reported that her husband, whenever he became violent, started throwing things at her and she was injured.

About 16 percent respondents said that their husbands tried to hit them or kick them. About 24 percent said that their husbands pushed them causing them physical injury. About 14 percent respondents reported that their husbands became so violent that they started beating them with shoe or with hands and kicked them hard with their legs (Table 4).

Respondents who reported physical violence also said that their husbands were too violent and aggressive. Those who had experienced physical violence during pregnancy also said that their husbands were drug users or unemployed, and they did not tolerate any thing which they perceived against them or against their will. Many respondents informed that they had experienced multiple forms of violence at the same time such as physical and verbal as well as various forms of physical and verbal violence such as kicking and pulling hair and using abusive language, or beating and using insulting language. They also had experienced violence several times during pregnancy.

Table 4

Forms of Physical Violence Respondents Experience

\begin{tabular}{|l|c|c|}
\hline Forms of Physical violence & Number & Percentage \\
\hline Hitting/Kicking & 8 & 16.00 \\
\hline Pushing & 12 & 24.00 \\
\hline Pulling hair & 8 & 20.00 \\
\hline Slapping & 12 & 24.00 \\
\hline Throwing objects & 6 & 12.00 \\
\hline Beating & 7 & 14.00 \\
\hline
\end{tabular}




\section{Sexual Violence during Pregnancy}

To know the incidence of sexual violence by the husband during last pregnancy few questions were asked by the respondents. Our findings show that it is difficult to measure sexual violence because of the traditional perception of most women who do not consider sexual violence as violence; they all considered it the right of their husbands to have sex with them whenever they want to have it. It is the right given to them by religion, they told us. None of them had the concept of forced sex. In response to a question about forced sex, after probing 30 percent respondents admitted to incidences of forced sex during pregnancy. Respondents said that "Having sex is husband's right and a wife must obey him, otherwise she will be thrown in hell on the Day of Judgment. If she wants to go to heaven then she must obey her husband."

In response to the question about the frequency of sexual relation during pregnancy in early months, 60 percent respondent told that it was less frequent. About 92 percent respondents said that they avoided sex after six months of pregnancy (Table 5). However, some women told that during pregnancy they wanted to avoid sex, because sometimes they were too tired, they had to do household chores.

Table 5

Sexual Behaviour during Last Pregnancy

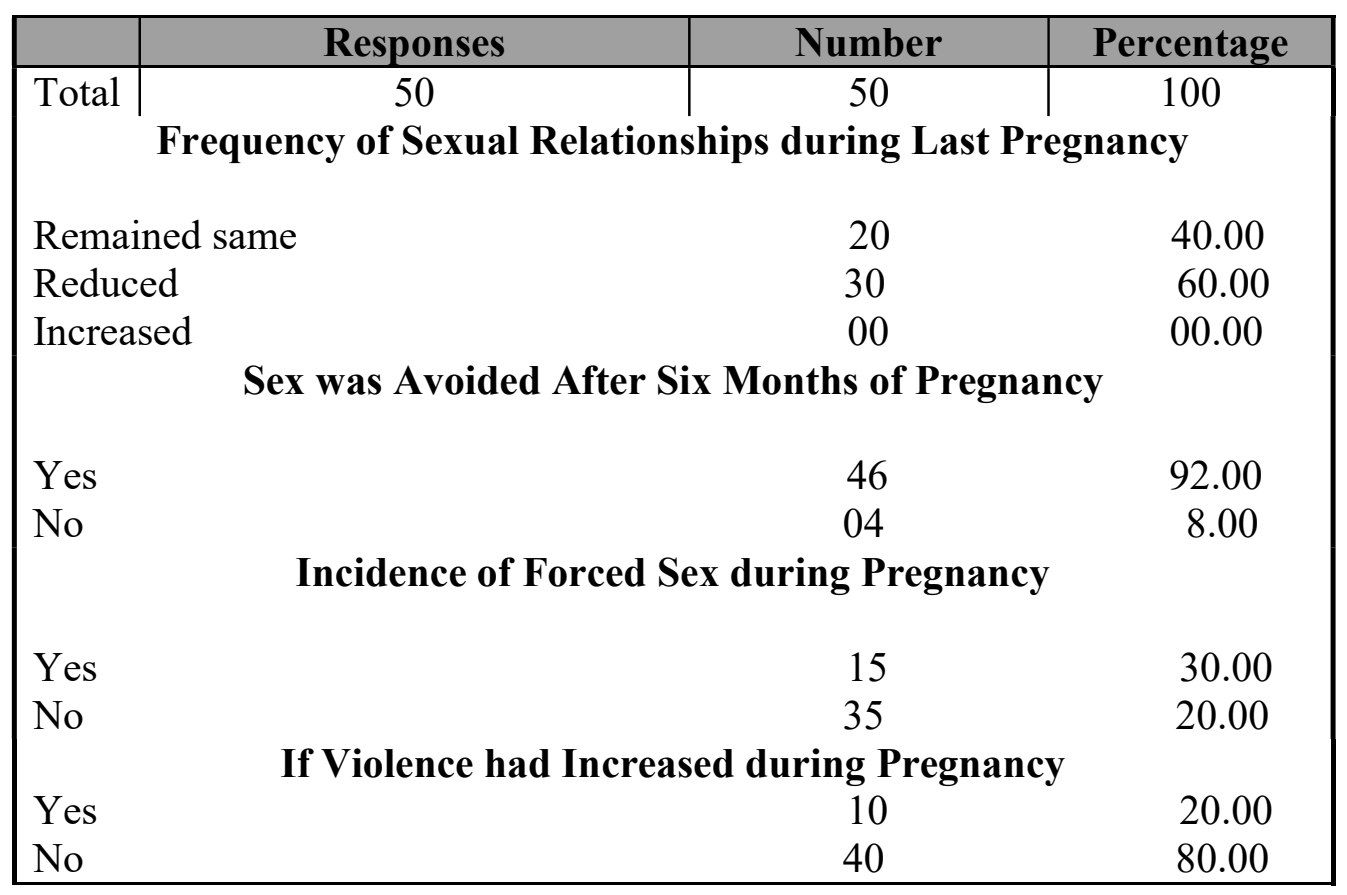


Table 5 shows that 20 percent respondents while reporting their husbands violent behaviour during their pregnancy also told us that they (husbands) also took care of them during pregnancy. Thus these women experienced both physical and verbal violence and caring by their husbands. They told us that their husbands would often brought food for them and helped them in household chores. Their behaviors were both positive and negative. Thus some women said that they did not bother much about their husband's violent behaviour as it was not a lasting mood.

Earlier research studies have shown that violence during pregnancy is linked to a history of violence prior to the pregnancy, and majority of women who are abused in pregnancy were also abused before and after the pregnancy (Compbell et al 2004). Findings of our study confirm the same. Nearly all respondent who faced violence during their last pregnancy informed that they were also abused before, it was not first time.

Table 5 presents the consequences of violence during pregnancy on their health or on health of their children. A large majority reported stress and tension and mental distress during pregnancy and even after child birth. They told that their mental state had impact on their physical and mental health.

About 20 percent women reported premature birth of their children and low birth weight of their babies, which they said was due to the violence they experienced during pregnancy. Four percent women reported pregnancy wastage due to violence. These women reported severe beating and kicking by their husbands during their first trimester. One woman reported that her child was born mentally retarded. She told that "My husband is a drug abuser and is too aggressive. During my last pregnancy he used to beat me and kick me. I was too weak; he never took care of me. He was always in need of money. I have five children. I do not want any more, but he wants more. He is not in favour of using birth control or family planning methods. It is actually very difficult to look and take care of mentally retarded child. He is about one year old, does not understand any thing. He is totally disabled; I am too worried for him. During my last pregnancy I had experienced violence, my husband pushed me, kicked me several times. Due to violence I had preterm birth. It was a difficult birth."

Two respondents reported pregnancy loss, due to violence. One respondent told that "it was the third month of my pregnancy. My mother-in-law was not happy with me, she ordered me to do some chores. I did not obey her. She told that to my husband and he became angry and pushed me, pulled my hair and kicked me, and bleeding was started. I lost my child." 
Table 6

Consequences of Violence during Pregnancy

\begin{tabular}{|l|c|c|}
\hline Reported consequences of violence & Number & Percentage \\
\hline Low birth weight of child & 10 & 20.00 \\
\hline Premature birth & 10 & 20.00 \\
\hline Child loss & 2 & 4.00 \\
\hline Bleeding & 4 & 8.00 \\
\hline Retarded child & 1 & 2.00 \\
\hline Back pain & 3 & 6.00 \\
\hline Stress/tension/depression & 6 & 52.00 \\
\hline
\end{tabular}

\section{Discussion and Conclusion}

Violence against women occurs in every country and among all socio-economic and religious groups. But it is evident from research studies that its prevalence is high in societies where women's status is inferior to men, where women are disempowered, and male control over resources is strong (Heise 1999). It is also revealed from studies that women who are abused rarely seek medical care for acute trauma. Abused women often live in fear and suffer depression, anxiety and post-traumatic stress (Compbell 2002). There are many forms of violence against women. Women are vulnerable to domestic violence or violence by husband or intimate partner during whole of their reproductive life and also in old age.

Violence during pregnancy is somewhat a neglected aspect, though its impact on health of women and children is devastating. In Pakistan one of the most common forms of domestic violence is the violence perpetuated by husbands. Domestic violence is rooted in cultural norms. In Pakistan society generally women's position in the family and in society is inferior relative to males. Women are expected to be submissive and males, especially husbands, want to have rights and control over lives of women. Males are supposed to be breadwinner, though it is not true in all situations. In many household women are the major earner, still they have to face discrimination and their status is inferior. However, women's disempowerment is one of the major reason of domestic violence, as well as institution of marriage and norms associated with marriage also the reasons of violence.

In Pakistani culture there is general agreement that husbands have the right over their wives, thus they have the right to beat them; punish them in order to control them. Domestic violence is justified under certain grounds and circumstances, such as not obeying her husband, not having food ready on time, going somewhere without husband's permission, failing to care children properly etc. or refusing sex, failing to perform her role and responsibilities properly, etc. Thus, a husband has a right to punish 
his wife. In fact domestic violence is rooted in cultural norms and women's lack of power in relationships.

It was observed during survey that respondents were reluctant to give answer of few questions, because they perceived that "it is a matter between a husband and wife, it is matter of private life and matter of family", thus they did not agree to disclose that. Further, respondents perceived that "it is right of husband to punish wife if she does not obey, or did some thing against her husband's wish". They also said it is the responsibility of a wife to provide peace at home and to her husband". One respondent said "My husband is aggressive and beats me, I try to keep silent. But I always pray for him, for his life, health and income, because he is my husband, he is the father of my children."

It was found that physical, verbal and sexual violence prevalent among respondents during pregnancy, but it is difficult to measure its extent and intensity accurately because of various definition of violence, various perception about it, perception of husband's right, and respondent's socio-cultural environment.

Respondents of the study reported a number of consequences of violence during pregnancies on them or on their fetus or children. These ranged from minor hurt to loss of babies and even disability among children. It shows that women are vulnerable and health impacts of violence are devastating. This study has some limitations. There is a strong need to conduct more research studies on this aspect in order to comprehend the seriousness of the threat and the vastness of its prevalence.

\section{References:}

Abbasi, R.A., Ara S., Syed Shershah (2003) Prevalence and Dynamics of Domestic Violence Among Pregnant Women In The Medical Spectrum, Vol. 24 No. 1, 2. $20034-5$

Asling-Moremi K, Pena R, Ellsberg M, Persson L. (2003) Violence Against Women Increases the Risk of Infant and Child Mortality. A Case-referent Study in Nicaragna, In The Bulletin of the World Health Organization Vol. 81: 10-18.

Bohn D. (1990) Domestic Violence and Pregnancy. Implications for Practice In Journal of Nursing and Midwifery Vol. 350: 86-98.

Campbell J, Garcia-Mareno C \& Sharps P. (2004) Abuse During Pregnancy in Industrialized and Developing Countries In Violence Against Women. Vol 10 No. 7: 770-789. 
Campbell I. et at. (2002) Health Consequences of Intimate Partner violence In The Lancet 359: 1331-1336.

Heise L, Ellsberg. M., Gottemeoller M. (1999) Ending Violence Against Women.

Population Reports, Series L, No. 11, Population Information Programme.

Hillard P.A. (1985) Physical Abuse in Pregnancy. Obstetrics and Gynecology. Vol 66: No. 2: $185-90$

Muhajarine N., and D”Arcy, C. (1999) Physical Abuse During Pregnancy: Prevalence and Risk Factors In Canadian Medical Association Journal. 160.7: 1007-1011.

Newberger, E.H., Barkan, S.E., Lieberman, ES., Miccormick., M.C., Yllo, K., Gary, L.T., and Schechter, S. (1992) Abuse of Pregnant Women and Adverse Birth Ontceme, Current Knowledge and Implications for practice In Journal of the American Association Vol. 267 No. 17: 2370 - 2372.

Stark E. Flitcraft A. Frazier W. (1979) Medicine and Patriarchal Violence: The Social Construct of a "Private" Event In The Journal of Health Service. Vol. 9: 461-93

United Nations General Assembly (1993) Declaration on the Elimination of Violence Against Women. Proceedings of the $85^{\text {th }}$ Plenary Geneva.

Valladares E, Et al (2002) Physical Partner Abuse During Pregnancy: A Risk Factor to Low Birth Weight in Nicaragua In Obstetrics and Gynecology Vol, 100 No 17:700-705

World Health Organization (2005) WHO Multi-country Study on Women's Health and Domestic Violence Against Women Geneva.

World Health Organization (1997) Violence Against women: A Priority Health Issue. WHO/FRH/WHD 97-8 WHO Geneva.

Shakila A. Rehman is an Associate Professor in the Department of Geography, University of Karachi, Pakistan. Her doctoral research is "Poverty in Karachi: Socioeconomic and Geographical Perspective". Her areas of interest are: Population and Gender Issue, Health Care and Migration.

Dr. Muhammad Shahid is an Associate Professor in the Department of Social Work, University of Karachi, Pakistan. His areas of interest are: Child Labour and Social Problems. 